\title{
Navigating Boundaries in Additive Manufacturing through Action Research
}

\author{
Katharina Ruckstuhl, Rafaela C. C. Rabello, and Sally Davenport
}

\author{
" Boundaries generate turbulence. Boundaries are encountered") \\ through exploration, and the process of exploration is messy \\ ... Yet, it is within this messiness and the associated tensions \\ of shared and differing perspectives, and often at the points \\ of intersections of diverse ideas, new possibilities emerge and \\ new solutions and/or approaches are generated, which, in \\ turn, inspire and lead to transformation.
}

Lonnie Rowell, Margaret Riel, and Elena Polush (2017b)

\begin{abstract}
Action research - both as praxis but also from a critical orientation - can elaborate modes of action, identifying the borders and margins that act as both the productive spaces for collaboration as well as the fuzzy areas that require reflection and clarification. In this exploratory case study, action research is used to follow an additive manufacturing project team in real time as it navigates fuzzy areas to integrate knowledge to produce commercializable science innovation in one of New Zealand's National Science Challenges (NSC): Science for Technological Innovation - Kia Kotahi Mai: Te Ao Pütaiao me Te Ao Hangarau (SfTI). Through action research as praxis and as critical orientation, we have identified key mechanisms in interdisciplinary and transdisciplinary research for commercialization, particularly in the context of New Zealand's indigenous Māori people. Our preliminary analysis indicates that an explicit understanding of the fuzzy spaces can help teams find creative and collaborative means to navigate the productive but challenging "interstices of disciplines" (Mengis et al., 2018) to produce science innovation and discoveries and to galvanize relationships with industry and Māori participants. The findings also indicate that action research can promote structural, relational, and knowledge changes within teams, helping them solve complex problems in real time.
\end{abstract}

\section{Introduction}

Recent research into "real world problems" (Carr et al., 2018) has noted the need for interdisciplinarity. Such aspirations have been a feature of "grand challenges", which galvanize collaborations between governments, academia, and industry, directing the science sector to pursue "societal goals" (Kaldewey, 2018) in areas as diverse as health and development, global food security, climate change, energy, and aging populations.

Action research - both as praxis but also from a critical orientation (Bleach et al., 2016; Rowell et al., 2017a) can elaborate modes of actions, identifying the borders and margins that act as both the productive spaces for collaboration as well as the "fuzzy" spaces that require clarification. In this study, we show how action re- search can be used to navigate such fuzzy spaces to help researchers understand how to integrate knowledge to produce commercializable science innovation in New Zealand's National Science Challenges (NSC). New Zealand has heavily invested in physical sciences and engineering research to grow the country's economy through a ten-year national science challenge: Science for Technological Innovation - Kia Kotahi Mai: Te Ao Pūtaiao me Te Ao Hangarau (SfTI).

The SfTI challenge has brought together interdisciplinary research teams to collaborate with enterprises - including Māori, New Zealand's indigenous people - to help unlock innovation and contribute to the country's economy. The combination of different specialized knowledge domains across numerous public and private organizations has the potential to both propel and obstruct innovation. If the SfTI approach to innova- 


\title{
Navigating Boundaries in Additive Manufacturing through Action Research
}

\author{
Katharina Ruckstuhl, Rafaela C. C. Rabello, and Sally Davenport
}

tion is to succeed, then it is important to look for ways to minimize or eliminate the barriers and increase or accelerate the innovation enablers, with such findings expected to be shared and incorporated more widely across the traditional science boundaries.

In order to build this evidence base, a team of social science researchers - the Building New Zealand's Innovation Capacity team (BNZIC) - has been following "in real time" the diverse projects that have been funded through SfTI. The BNZIC team has adopted an action research approach to identify the tensions and the structural and relational mechanisms that inhibit and promote innovation knowledge transfer. The team adopted two action research modes: action research as praxis and action research as critical orientation. Through these two modes, the BNZIC team has identified that research interstices, in both their physical and abstract forms (Corsaro, 2018; Huang \& Huang, 2013), should be consciously foregrounded in interdisciplinary and transdisciplinary research to accelerate such teams' progress towards their innovation objectives and to more consciously include Māori participants who might contribute towards such innovation. Such foregrounding has allowed the BNZIC team to provide reflections back to the science teams to help them understand the processes, people, and resources required to achieve the SfTI mission.

This article presents a deep inquiry (Riel, 2010) into individual and team practices from one of the SfTI projects: additive manufacturing. In this context, deep inquiry refers to cyclical and interactive processes of observing, planning, acting, and reflecting (Piggot-Irvine, 2009) upon the additive manufacturing team's innovation processes. The question that has guided this inquiry is: How can action research, as praxis and critical orientation, help interdisciplinary teams transform science innovation processes, particularly in the context of engagement with Māori? The article aims to show how being attentive to the fuzzy spaces between individuals and groups helps navigate the productive but challenging "interstices of disciplines" (Mengis et al., 2018: 2; Nicolini et al., 2012) to produce science innovation and to galvanize engagement with business and Māori.

The article is divided into four sections. The first introduces the broader SfTI mission and the additive manufacturing programme. The second describes the research design methods and provides a brief outline of the data collection and analysis processes. The third addresses the question of action research as transformat- ive praxis, outlining action research theory in reference to critical design and boundary object theory, to explicate how the research scientists are transforming practice to solve complex technical problems. The fourth section concerns action research as critical orientation and explores how this approach is promoting relational and knowledge changes within the additive manufacturing team, to help them critically reflect upon their engagement with Māori participants. We begin by introducing the SfTI challenge.

\section{The SfTI National Challenge}

The Science for Technological Innovation, Kia Kotahi Mai: Te Ao Pütaiao me Te Ao Hangarau, (SfTI) challenge aims to enhance New Zealand's capacity to use physical sciences and engineering for economic growth through its scientific innovation and discoveries. The challenge aims to incorporate New Zealand's human, relational, and technological capacities to grow the country's economy. The contention is that a more technology-driven and prosperous economy will emerge from more focused and connected research efforts (Daellenbach et al., 2017; Davenport et al., 2015; SfTI, 2018). SfTI funds projects in the areas of sensors, robotics and automations, IT, data analytics and modelling, and materials, manufacturing, and design.

Along with investment into the technical science, SfTI supports a capacity development programme, so that scientists might become more confident in leading conversations with and being more proactive in their engagement with industry partners, including Māori. This latter requirement is because of the Vision Matauranga (Māori knowledge) science policy, which has become a required consideration for all science funding in New Zealand (Daellenbach et al., 2017; Davenport et al., 2015; MoRST, 2007). In response to this policy, SfTI has developed three pillars: to advance Māori knowledge; to have more Māori leading and participating in technological research; and to bring greater benefit to Māori by prioritizing and tailoring research for Māori (SfTI, 2018).

Over 250 researchers and 29 different organizations from across New Zealand and internationally are involved in SfTI projects (SfTI, 2018). SfTI allocates funding to two levels of research: large "Spearhead" projects and smaller "Seed" projects. There are eight Spearhead Projects, four of which commenced in 2016, of which one - the 3D/4D additive manufacturing of biopolymers - is the subject of this case study, and to which we now turn. 


\title{
Navigating Boundaries in Additive Manufacturing through Action Research
}

\author{
Katharina Ruckstuhl, Rafaela C. C. Rabello, and Sally Davenport
}

\section{SfTI's additive-manufacturing project}

Additive manufacturing, or 3D/4D-printing technology, is where physical objects are created by building up parts through the laying of materials from powder or liquid combined with a binding agent such as heat, UV light, or laser (André, 2017a; Horvath, 2014; Khare et al., 2017; Zeidler et al., 2018). 3D-printed objects are static compared to $4 \mathrm{D}$-printed objects that actuate through triggering (sensing) elements (e.g., water and light) embedded within their underlying material (Tibbits, 2014; Tibbits et al., 2014). A 4D object's actuation is independent of external devices or electromechanical systems, and it is constructed using a 3D-printing platform combined with a $3 \mathrm{D} / 4 \mathrm{D}$ printing interface in a singular system (Khare et al., 2017; Tibbits, 2014; Tibbits et al., 2014).

Additive manufacturing enables flexible production of personalized products, with reduced costs of production and wastage of feedstock resources (André, 2017a; Weller et al., 2015). It also allows for fast prototyping by reducing the number of intermediaries between the designer and the final product, speeds up product creation and production time, and reduces storage costs (André, 2017a, b). 3D/4D printing technology also poses challenges, in particular, the manufacturing feedstock that is mostly from non-renewable sources, which poses environmental dangers (Huang \& Huang, 2013; Zeidler et al., 2018).

Responding to such opportunities and challenges, a geographically dispersed, cross-disciplinary team, composed of chemists, engineers, and designers, is working towards developing bio-based $3 \mathrm{D} / 4 \mathrm{D}$ materials and equipment in New Zealand (Zeidler et al., 2018). To confirm that this new technology is attuned to market demands (Edwards, 2005; Mäenpää et al., 2016) the team has built-in regular engagement with industry.

Combining knowledge across different specialized domains can either propel or impede innovation. This depends on how knowledge is shared, incorporated, and transformed across boundaries (Carlile, 2004; Corsaro, 2018). According to Hsiao, Tsai, and Lee (2012), a boundary refers to the limits or the interstices of a domain, which may be "physical, geographical, social, cognitive, relational, cultural, temporal/spatial, divisional, occupational, and disciplinary".

Recognizing boundaries is an essential part "of systems work/inquiry/thinking” (Williams \& Imam, 2007 in Rowell, Riel, \& Polush, 2016). Such recognition raises actors' awareness of the tensions in boundaries, open- ing up dialogical spaces to transform and catalyze knowledge (Rowell et al., 2017a). Recognition of these boundaries through the BNZIC team's action research with the science team in the context of their interactions with industry and Māori aims to transform science innovation praxis - both practically and critically. We now explore the research design and methods.

\section{Research Design and Methods}

This is an exploratory case study that was conceived as a "real-time" examination with the BNZIC team of social scientists following the additive manufacturing team as they developed their ideas and technologies. An ethnographic approach (Agar, 1996; Gibson-Graham, 2014; Hymes, 2013) was chosen given the exploratory nature of the science in a newly-formed science team with a very broad mandate to develop novel and commercializable research. The BNZIC researchers used a range of data collection methods including observations and active participation at team meetings and social occasions; examination of science reports and emails; informal and formal interviews; and surveys.

This case study draws on the draft report and presentation supplemented by the additive manufacturing team's science reports, as well as broader SfTI reports about the additive manufacturing team's research. These reports are complemented by 28 semi-structured and open-ended interviews with the additive manufacturing team members as well as participants who took part in the team's workshops with industry. These interviews took place over a 30-month period and were audio recorded then transcribed (Lapadat, 2000; Lapadat \& Lindsay, 1999; Scheurich, 1995). A qualitative data analysis software package, NVivo, was used to organize and code data with an inductive approach adopted to analyzing the data (Braun \& Clarke, 2006).

In the following section, we give a brief overview of the aims and processes of action research. We then assess how this approach has informed the additive manufacturing team to transform science and engagement practice.

\section{Transforming Praxis in the SfTI Additive- Manufacturing Project}

Action research refers to a participatory process that seeks to bring together practice, theory, and reflexivity in order to develop practical solutions (Reason \& Bradbury, 2001). In the additive-manufacturing project, two 


\section{Navigating Boundaries in Additive Manufacturing through Action Research}

\section{Katharina Ruckstuhl, Rafaela C. C. Rabello, and Sally Davenport}

orientations of action research were combined: pragmatic and critical (Hadfield, 2012; Johansson \& Lindhult, 2008). Within a pragmatic orientation, researchers and practitioners reflect upon their ongoing process of engagement and knowledge creation to act concurrently to overcome existing obstacles. Within a critical orientation, researchers and practitioners interrogate power relations (Johansson \& Lindhult, 2008). In the additive manufacturing project, coordinated action was needed to create new innovation knowledge for commercialization (pragmatic orientation) while critical reflection (critical orientation) was required to transform knowledge and relationships between researchers and Māori.

Pragmatically oriented action research is often composed of a hybrid methodology that aims to connect theory to practice. Rowell and co-authors (2017a) emphasize that co-constructing common ground between researchers and practitioners creates the platform for action. To establish this common ground, the BNZIC team took a "spiral of steps" approach (Lewin, 1946; Minkler, 1981) by attending 13 formal meetings, workshops, and team-building functions (dinners and laboratory visits); observing and taking part in presentations; and offering regular formal and informal reflections at the individual and group levels. This embedded but reflexive participatory approach enabled some key insights to be shared.

The first insight is how design acts as an upstream innovation catalyst through the iterative embodiment of innovation prototypes based on the designers' understanding of the scientists' technically uncertain research. By identifying how design literally objectifies boundaries between the downstream understandings and expectations of end users and the upstream scientific invention of the researchers, the BNZIC team showed the value of design in very early science. Designers are more commonly used as a mid-stream mechanism (Luo, 2015), when the technical uncertainties of the science have been worked out and the researchers have set the direction for the science (Friesike et al., 2015; Schuurbiers \& Fisher, 2009). In the additivemanufacturing project, the designers have worked in tandem with the scientists to act as boundary intermediaries between the uncertainty of the scientists' new technology and the market demand of industry. This is an important consideration for not only the additivemanufacturing team but also the wider SfTI challenge.

The following quotation exemplifies how many of the scientists felt during early meetings with industry:

\begin{abstract}
"Well the problem is that the meeting was all about what they [emphasis added] wanted; so one group ... wanted us to print an airline seat and all kinds of weird things. I'm scared they get disappointed when they now hear we're actually dealing with science stuff and we're not actually focusing on one end product." (Additive-manufacturing scientist)
\end{abstract}

The comments that the meetings were all about what they (i.e., industry) wanted and that the project was really about "science stuff" can be considered an example of a "cognitive trap" where participants draw quick conclusions based on their own experiences and expectations rather than on direct observation and interaction with others (Butler \& Roberto, 2018). Such cognitive traps interfere with knowledge co-creation at a boundary interstice because they hinder collaboration. In contrast, Butler and Roberto (2018) identify that a design-led approach creates pathways to connect theory and practice by first developing empathy, and then through the ideation and prototyping-testing processes.

Developing empathy is a "human-centred" process (Kimbell, 2011) supporting understandings about and expectations of end users. A key feature of the additivemanufacturing project has been its formalized meetings with industry representatives. Involving companies upstream has been a boundary challenge requiring skilled facilitation. Initially, a business facilitator was used to identify industry's interest in 3D-printed biomaterials, however, subsequent meetings have focussed more on developing shared understanding of what makes an impact for industry. Developing empathy for industry's viewpoint, needs, and concerns has been an iterative process. A professional external contractor skilled in bridging diverse worldviews has been employed to explore not only the possibilities of the unknown science but also to allow both scientists and industry to "understand each other's language" (Additive-manufacturing scientist). The shift from the concerns expressed in an early workshop to a more collaborative understanding is expressed in the following:

"[The] team came together with members all in one room. Wouldn't have expected to get that far in one day. Eight organizations with people from different sectors and capabilities. Intense and focused and good will and wanting to make it work." (Additive-manufacturing participant)

What part did BNZIC play in this iteration? While the leadership team had planned for regular interaction 


\section{Navigating Boundaries in Additive Manufacturing through Action Research} Katharina Ruckstuhl, Rafaela C. C. Rabello, and Sally Davenport

with industry, the draft report after the first year showed the value of continuing to focus on empathy development between industry and science as opposed to a process of merely listening to industry as evident in the initial meeting. In other words, research focus on the pragmatics of empathy has reinforced and confirmed a practice in this upstream science, giving confidence to continue in this direction. Additionally, this finding posits that empathy intermediaries are not only a "nice to have" at the start of a science process, but can play an important role throughout the innovation process enabling industry to have early insight into the science. Co-innovation, rather than a theoretical concept, becomes more of a reality with such an approach.

Empathy has also been key to supporting the ideation process. Design-led ideation entails brainstorming possible solutions to meet the needs and expectations of end users (Butler \& Roberto, 2018) and to turn science problems into innovation opportunities (Kimbell, 2011). As identified in the additive manufacturing team's research mission, the printing of bio-based materials was the focus of the science because:

“... at the time, there were none [sic] other than the medical tissue stuff ... and so, basically, 3D printing was built on the standard petroleum, plastics, and metals. And still predominantly is. At the time we found ... there's still not a bio-base out there." (Additive-manufacturing scientist)

However, identifying an opportunity is one thing: turning it into reality with a newly formed team is another. Unsurprisingly, there was an "element of frustration" as the team struggled to understand the linkages between their science, the role of the designers within the science and the expectations of industry.

\footnotetext{
"At one end, we've got a selection of materials that people think might be useful and, at the other end, we've got, well, what applications we want to use them for. So, how to join those up? And I think, at some point, it's a ... look there is no right answer, there's no wrong answer, let's agree on a focus and just get on and do it." (Additive-manufacturing scientist)
}

In relation to the "how to join" problem, it was the designers who provided the impetus for the scientists to "agree on a focus". There had been a "split of opinions" as to whether to focus on "physical products" or "new technologies or processes" (Additive-manufacturing scientist). This was resolved when, through a repetitive series of design offerings that included speculative articulations of future 3D/4D scenarios, current products printed using novel design approaches, and experimental design methods, the scientists agreed to integrate their efforts by printing demonstrators that combined the novel chemical materials with the equipment modifications needed to print the materials. From a design perspective, a demonstrator or physical prototype can facilitate knowledge transfer, translation, and transformation across interdisciplinary teams (Jensen \& Kushniruk, 2016). Such prototypes "elicit a more nuanced understanding of product attributes ... facilitating future iterations of design" (Henderson, 1995; Seidel \& O'Mahony, 2014: 694; Stigliani \& Ravasi, 2012), thus helping to "describe a potential future worth testing" (Bletcher, 2017).

Physical prototypes are also boundary objects: common points of reference that can facilitate or act as barriers to effective knowledge sharing, co-ordination, and transformation among individuals and institutions of different specialized domains (Corsaro, 2018). In other words, boundary objects are conduits to cross knowledge boundaries (Marheineke, 2016).

The following illustrates how the role of the BNZIC researcher enabled reflection on prototypes as boundary objects through the collaborative process:

BNZIC researcher: "Now that you've got some prototypes or some targets that you're all agreed on, that's actually liberated everybody to..."

Additive-manufacturing scientist: "At least this, now also when we have the meetings, you can ... say, all right, you've made an ultra-light material what will you use it for? Up 'till that point it was, you make material and then look for a solution for a problem that it could resolve. Whereas now it is, okay - swimming fin, for example."

In the above excerpt, while the term "boundary object" (the swimming fin) is not mentioned by the BNZIC researcher, the question allowed the scientist to reflect on the positive shift from the frustration of the "openended exploration" (Stappers, 2013) or the "suck it and see" approach described by one scientist. Subsequent to the above interview, the BNZIC researcher has introduced the idea of the boundary object as a way for the team to understand collectively some of the fuzzy boundary interstices that may have led to their earlier frustration. This concept has also allowed them to have 


\title{
Navigating Boundaries in Additive Manufacturing through Action Research
}

\author{
Katharina Ruckstuhl, Rafaela C. C. Rabello, and Sally Davenport
}

a greater appreciation of why the design-led approach, which initially was not well understood by either the scientists or the designers has accelerated the science. Design has helped integrate not only their collaborative science but also created better empathy with industry to the extent that:

"there is a real sense of excitement from industry in terms of seeing quite tangible outcomes ... I think they got an understanding of what it was all about, and what was planned." (Workshop facilitator)

In the next section, we move from action research as praxis to action research as critical orientation, and the "spiral of steps" approach (Lewin, 1946) that has been necessary to facilitate new thinking and new action.

\section{Transforming Additive-Manufacturing En- gagements through Critical Orientation}

Action research as critical orientation involves taking a critical stance regarding issues of social injustice and draws on the works of diverse critical traditions (Hadfield, 2012; Johansson \& Lindhult, 2008; Rowell et al., 2017a). As such, it is emancipatory and calls for the recognition of tensions and conflicting interests between unbalanced power relations (Rowell et al., 2017a; Rowell et al., 2017b). Within the New Zealand context, unbalanced power relations apply to the situation between Māori and Pākehā (non-Māori, largely European New Zealanders) because of New Zealand's colonial legacy. This history marginalized Māori lifeways and, through the alienation of land as an economic resource, led to disproportionate levels of socio-economic deprivation (Rewi \& Rātima, 2018). These processes continue to reproduce unequal power relations between Pākehā and Māori (Smith, 2009), particularly as it relates to Māori science knowledge, or mātauranga. New Zealand's Vision Mātauranga (VM) science policy, aims to "unlock the innovation potential of Māori knowledge, resources and people to assist New Zealanders to create a better future" (MoRST, 2007). However, with few Māori scientists in R\&D technical areas such as additive manufacturing, Māori knowledge and the accompanying human and relational capacity to work with Māori communities and businesses is inhibited. Hence, the BNZIC researchers, one of whom is Māori, adopted a critical orientation to analyze the human and relational capacities of the additive manufacturing team and to explore opportunities to implement the VM policy in a way that addressed power imbalances within the science.
A critical perspective emphasizes that reality is subjective and construed through power hierarchies (Lather, 2006) thus shaping human relations (Kincheloe \& McLaren, 2002). In this article, we adopt MacDonald and co-authors' (2002) critical positioning that some groups in society are powerful, while others are powerless or less powerful. Powerful groups have interest in maintaining the power status quo. This can be seen in the initial formation of the additive-manufacturing scientists and in the early engagements with industry where Māori were not represented, despite biomaterials derived from indigenous flora or fauna being of key interest to Māori, who regard these as "taonga" or inherently precious. Many tribal groups list such taonga within their traditions and within legislation where tribes have legal agreements or settlements with the government.

While the leadership team was aware of the need to address VM, the ability to enact this within the science itself or with industry-focused Māori relationships proved challenging. Some team members viewed the VM policy as the Government:

“... pushing their tokenism down the line and expecting us to do tokenistic things to solve problems that they've identified. I think it's a little bit contrived. They're trying to make it genuine, but it's still - the framework, in my opinion, is quite tokenistic."

Other team members rhetorically refrained from recognizing or legitimizing VM as one of SfTI's aspirations as in the following:

"Sorry, when you say VM policy; whose [italics added] policy?"

Action research as critical orientation requires bringing into consciousness the reality of occupying powerful or less-powerful positions, and finding fresh meanings for a newly revealed reality (Freire, 1987). Disrupting notions that VM is "tokenistic" or is someone else's concern - "whose policy?" - involves struggle and resistance that is often unconscious to the individual (Johansson \& Lindhult, 2008; Macdonald et al., 2002). For the BNZIC team, the VM policy and how it is implemented at the site of science production, is a border that requires considerable interrogation if Māori knowledge and engagement for innovation are to be "genuine". This will require the powerful - in this, case scientists - to "liberate" themselves from long-standing power imbalances by assuming an active role with 


\title{
Navigating Boundaries in Additive Manufacturing through Action Research
}

\author{
Katharina Ruckstuhl, Rafaela C. C. Rabello, and Sally Davenport
}

Māori via "dialogue" (Freire, 1987). This is more than having a "token" relationship, as expressed above. Rather, it is the practice of challenging and disputing words and ideals expressed in spoken and written words (Freire, 1987; McLaughlin \& DeVoogd, 2004), including understanding that language, as social practice, is connected intrinsically with broader social and political concerns (Freire \& Macedo, 1995) as is expressed in a policy like VM.

Such a "dialogical space" is a work in process for the scientists. In the first instance, the team sought to introduce Māori high school students to 3D technology, a practice that might be seen as an educative activity that maintains the power status quo (i.e., the more powerful "bringing" technology to the less powerful). When asked about the utility of this approach, the BNZIC team assessed that it would not meet the team's science objective, thus this activity was not pursued. However, within the team itself, some individuals could see the transformative potential of Māori knowledge. For example, one scientist described how waste from Māori fisheries had the potential to become additive manufacturing feedstock, and another posited that Māori design concepts might offer potential novel design pathways. These insights were relayed back to the science leadership team to identify that there were opportunities for further Māori innovation engagement.

Being open to the VM dialogic space as a site of innovation opportunity - Freire's (1987) newly revealed reality - has been activated through the broader SfTI capacity development programme, with one scientist noting that:

“... the workshops they conducted at University of Auckland, particularly around Vision Mātauranga and all that; it was really helpful ... I had a better idea of what it actually means. So, it is allowing me to address these issues [engagement with VM] in a better way than what I could have done before the whole thing started. So, it opened up a better insight into the process."

Another scientist confessed that:

“... maybe I rolled my eyes at [VM] about two years ago ... I now really love sitting down with, not just a Māori researcher, but sitting down with somebody with a Māori perspective - around why is this material so special to you - what is the significance of this region - why are we concerned about this fish waste product, and not concerned about the economy, but what does it mean to you as a people?"

While these human capacity activities have been helpful to destabilize notions that Māori are powerless bystanders in science endeavours, they have not transformed the performance of the actual science itself, in either its design or its participants. To achieve this outcome requires stronger measures. As suggested by the BNZIC team, Māori artists and technicians from a national Māori arts and crafts training school were invited to the third industry workshop. Positioning the Māori artists as equivalent to industry moves the artists from the "token" to the "innovation" dialogic space. While a useful step in that the discussions at the workshop involved understanding the innovation potential of $3 \mathrm{D}$ and 4D materials and objects for Māori, such a positioning still does not truly deal with the "power structures" (Geib, 2017) of science itself. For this to occur, the BNZIC Māori researcher has suggested that the additivemanufacturing team step out of their laboratories and engage in the Māori world. In other words, the dialogic space is a literal space, where power relations are reversed. The traditional Māori meeting space, the marae, is one where Māori language is spoken; where tikanga (Māori norms) govern relationships; and where mātauranga, traditional and transformative Māori knowledge, provides the underpinning framework for science innovation. The impact of such dialogue will be observed as the science unfolds in the forthcoming years.

\section{Conclusion}

This article presents initial findings from an additivemanufacturing case study, to show how action research can elucidate the fuzzy but productive boundaries that underpin science innovation processes. The article aimed to address how action research - both as praxis and as critical orientation - can help interdisciplinary teams transform science innovation processes to connect with end users, whether industry or Māori.

As the case study indicates, action research as praxis has shown that upstream design-led approaches that focus on the creation of empathy, ideation, and prototyping can accelerate knowledge transfer across science disciplinary and science-industry boundaries. This understanding shows that incorporating design thinking in upstream exploratory science has value - both in the way that it creates relational empathy for end users but also as a way to resolve technical issues by co-ordinating action around actual objects. As critical orientation, 


\section{Navigating Boundaries in Additive Manufacturing through Action Research}

\section{Katharina Ruckstuhl, Rafaela C. C. Rabello, and Sally Davenport}

the action research approach has identified the need for dialogic space to be opened up, requiring the literal border crossing from the laboratory to the marae if issues of power within the science system are to be reconfigured to take advantage of Māori innovation knowledge.

Findings from this research have both theoretical and practical implications that are intended to be shared and implemented not only with the additive manufacturing team but also across the broader SfTI challenge. Additionally, we have shown the value of action research in the innovation space within the context of the broad aspirations of science challenges to address realworld problems. Despite the messiness and tensions, it is only through exploring and reflecting on such differing perspectives at the margins of disciplines and organizations that transformative change can be enacted.

Citation: Ruckstuhl, K., Rabello, R. C. C., \& Davenport, S. 2019. Navigating Boundaries in Additive Manufacturing

(cc) BY

through Action Research. Technology Innovation

Management Review, 9(4): 7-16.

http://doi.org/10.22215/timreview/1229

Keywords: action research, transformative praxis, critical orientation, science, innovation, SfTI

\section{About the Authors}

Katharina Ruckstuhl is an Associate Dean at the Otago Business School, University of Otago, New Zealand. She also holds a PhD from Otago. Dr Ruckstuhl co-leads the "Building New Zealand's Innovation Capacity" social science research of the National Science Challenge, Science for Technological Innovation. She is also the Vision Mătauranga (Māori knowledge) leader, a "Theme" that crosses all of the Challenge's research activities. She has published in the areas of: Māori language; resource extraction in Māori territories; Māori entrepreneurship in SMEs; Indigenous science and technology; and Indigenous knowledge.

Rafaela C. C. Rabello holds a PhD in Social Investment in the oil and gas sector and a Master's degree in Education, awarded with distinction by the University of Otago, New Zealand. Rafaela also holds a BA in Psychology from the University Center of Brasilia, Brazil. Rafaela has worked within the fields of corporate social responsibility - in the oil and gas sector - and education for more than 10 years. She has published in the areas of: corporate social responsibility; social investment in the oil and gas sector; higher education and good teaching and effective learning methodologies in higher education.

Sally Davenport is a Professor of Management at Victoria University of Wellington, New Zealand. Sally is the Director of the New Zealand National Science Challenge "Science for Technological Innovation" (SfTI). Sally's academic life began as a research chemist, but she now has research interests covering the commercialization of scientific research, entrepreneurship and the growth of hightech firms, innovation strategy, and policy. Sally has previously led major research projects on competitive advantage in New Zealand firms, into organizations, and networks in biotechnology. Sally is a Commissioner with the New Zealand Productivity Commission and is also an Adjunct Professor in the College of Business and Economics at the Australian National University, a Fellow of the International Society for Professional Innovation Management, and a member of Global Women. In 2018, she was made a Member of the New Zealand Order of Merit for her services to science. 


\section{Navigating Boundaries in Additive Manufacturing through Action Research Katharina Ruckstuhl, Rafaela C. C. Rabello, and Sally Davenport}

\section{References}

Agar, M. H. 1996. The Professional Stranger: An Informal Introduction to Ethnography. New York: Academic Press.

André, J.-C. 2017a. From Additive Manufacturing to 3D/4D Printing 1: From Concepts to Achievements. Hoboken, NJ: John Wiley \& Sons.

André, J.-C. 2017b. From Additive Manufacturing to 3D/4D Printing 2: Current Techniques, Improvements and Their Limitations. Hoboken, NJ: John Wiley \& Sons.

Bleach, J., Feldman, A., Kim, M., McAteer, M., McNiff, J., Polush, E., Riel, M., Rowell, L., Santos, D., Shosh, J., Thomas, S,. Wamba, N., \& Wood, L. 2016. ARNA Symposium: The Palgrave International Handbook of Action Research. Paper presented at the Conference of the Action Research Network of the Americas, Knoxville, TN.

Bletcher, J. 2017. The Constellation: A Framework for Conceptualising Design as a Process of Innovation. The Design Journal, 20 (Sup 1): S4552-S4564.

https://doi.org/10.1080/14606925.2017.1352952

Braun, V., \& Clarke, V. 2006. Using Thematic Analysis in Psychology. Qualitative Research in Psychology, 3(2): 77-101. https://doi.org/10.1191/1478088706qp063oa

Butler, A. G., \& Roberto, M. A. 2018. When Cognition Interferes with Innovation: Overcoming Cognitive Obstacles to Design Thinking: Design Thinking Can Fail when Cognitive Obstacles Interfere; Appropriate Cognitive Countermeasures Can Help Disarm the Traps. Research-Technology Management, 61(4): 45-51. https://doi.org/10.1080/08956308.2018.1471276

Carlile, P. R. 2004. Transferring, Translating, and Transforming: An Integrative Framework for Managing Knowledge Across Boundaries. Organization Science, 15(5): 555-568. http://doi.org/10.1287/orsc.1040.0094

Carr, G., Loucks, D. P., \& Blöschl, G. 2018. Gaining Insight into Interdisciplinary Research and Education Programmes: A Framework for Evaluation. Research Policy, 47(1): 35-48. https://doi.org/10.1016/j.respol.2017.09.010

Corsaro, D. 2018. Crossing the Boundary between Physical and Digital: The Role of Boundary Objects. IMP Journal, 12(2): 216-236. https://doi.org/10.1108/IMP-06-2017-0036

Daellenbach, U., Davenport, S., \& Ruckstuhl, K. 2017. Developing Absorptive Capacity for Midstream Science in Open Innovation Contexts. International Journal of Technology Transfer Commercialisation, 15(4): 447-462.

https://doi.org/10.1504/IJTTC.2017.089674

Davenport, S., Daellenbach, U., Ruckstuhl, K., Hyland, M., \& Leitch, S. 2015. Rethinking Absorptive Capacity for Open Innovation Contexts. Presented at the ISPIM Innovation Symposiumm, December 6-8, 2015, Brisbane, Australia.

Edwards, A. 2005. Relational Agency: Learning to Be a Resourceful Practitioner. International Journal of Educational Research, 43(3): 168-182.

https://doi.org/10.1016/j.ijer.2006.06.010

Freire, P. 1987. Pedagogia do oprimido. Rio de Janeiro: Paz e terra.

Friesike, S., Widenmayer, B., Gassmann, O., \& Schildhauer, T. 2015. Opening Science: Towards an Agenda of Open Science in Academia and Industry. The Journal of Technology Transfer, 40(4): 581-601.

https://doi.org/10.1007/s10961-014-9375-6
Geib, C. 2017. How Much Should Expectation Drive Science? Answers to the Biggest Mysteries May Lie Well Outside Traditional Paradigms. Dark Matter, March 2017.

Gibson-Graham, J. K. 2014. Rethinking the Economy with Thick Description and Weak Theory. Current Anthropology, 55(S9): S147-S153.

https://doi.org/10.1086/676646

Hadfield, M. 2012. Becoming Critical Again: Reconnecting Critical Social Theory with the Practice of Action Research. Educational Action Research, 20(4): 571-585.

https://doi.org/10.1080/09650792.2012.727647

Henderson, K. 1995. The Political Career of a Prototype: Visual Representation in Design Engineering. Social Problems, 42(2): 274-299. https://doi.org/10.2307/3096905

Horvath, J. C. 2014. Mastering 3D Printing. New York: Apress. https://doi.org/10.1007/978-1-4842-0025-4

Hsiao, R. L., Tsai, D. H., \& Lee, C. F. 2012. Collaborative Knowing: The Adaptive Nature of Cross-Boundary Spanning. Journal of Management Studies, 49(3): 463-491. https://doi.org/10.1111/j.1467-6486.2011.01024.x

Huang, E. Y., \& Huang, T. K. 2013. Exploring the Effect of Boundary Objects on Knowledge Interaction. Decision Support Systems, 56: 140-147. https://doi.org/10.1016/j.dss.2013.05.012

Hymes, D. 2013. Foundations in Sociolinguistics: An Ethnographic Approach. Abingdon, UK: Routledge.

Jensen, S., \& Kushniruk, A. 2016. Boundary Objects in Clinical Simulation and Design of eHealth. Health Informatics Journal, 22(2): 248-264.

https://doi.org/10.1177/1460458214551846

Johansson, A. W., \& Lindhult, E. 2008. Emancipation or Workability? Critical versus Pragmatic Scientific Orientation in Action Research. Journal of Action Research, 6(1): 95-115. https://doi.org/10.1177/1476750307083713

Kaldewey, D. 2018. The Grand Challenges Discourse: Transforming Identity Work in Science and Science Policy. Minerva, 56(2): 161-182.

https://doi.org/10.1007/s11024-017-9332-2

Khare, V., Sonkaria, S., Lee, G.-Y., Ahn, S.-H., \& Chu, W.-S. 2017. From $3 \mathrm{D}$ to $4 \mathrm{D}$ Printing-Design, Material and Fabrication for MultiFunctional Multi-Materials. International Journal of Precision Engineering Manufacturing-Green Technology, 4(3): 291-299. https://doi.org/10.1007/s40684-017-0035-9

Kimbell, L. 2011. Rethinking Design Thinking: Part I. Design Culture, 3(3): 285-306.

https://doi.org/10.2752/175470811X13071166525216

Kincheloe, J. L., \& McLaren, P. 2002. Rethinking Critical Theory and Qualitative Research. In Ethnography Schools: Qualitative Approaches to the Study of Education: 87-138. https://doi.org/10.1007/978-94-6091-397-6_23

Lapadat, J. C. 2000. Problematizing Transcription: Purpose, Paradigm and Quality. International Journal of Social Research Methodology, 3(3): 203-219. https://doi.org/10.1080/13645570050083698 


\section{Navigating Boundaries in Additive Manufacturing through Action Research Katharina Ruckstuhl, Rafaela C. C. Rabello, and Sally Davenport}

Lapadat, J. C., \& Lindsay, A. C. 1999. Transcription in Research and Practice: From Standardization of Technique to Interpretive Positionings. Qualitative Inquiry, 5(1): 64-86.

https://doi.org/10.1177/107780049900500104

Lather, P. 2006. Paradigm Proliferation as a Good Thing to Think With: Teaching Research in Education as a Wild Profusion. International Journal of Qualitative Studies in Education, 19(1): 35-57.

https://doi.org/10.1080/09518390500450144

Lewin, K. 1946. Action Research and Minority Problems. Journal of Social Issues, 2(4): 34-46.

https://psycnet.apa.org/doi/10.1111/j.1540-4560.1946.tb02295.x

Luo, J. 2015. The United Innovation Process: Integrating Science, Design, and Entrepreneurship as Sub-Processes. Design Science, 1: E2.

https://doi.org/10.1017/dsj.2015.2

Macdonald, D., Kirk, D., Metzler, M., Nilges, L. M., Schempp, P., \& Wright, J. 2002. It's All Very Well, in Theory: Theoretical Perspectives and Their Applications in Contemporary Pedagogical Research. Quest, 54(2): 133-156.

https://doi.org/10.1080/00336297.2002.10491771

Mäenpää, S., Suominen, A. H., \& Breite, R. 2016. Boundary Objects as Part of Knowledge Integration for Networked Innovation. Technology Innovation Management Review, 6(10): 25-36. https://doi.org/10.22215/timreview/1025

Marheineke, M. 2016. Designing Boundary Objects for Virtual Collaboration. Berlin: Springer.

McLaughlin, M., \& DeVoogd, G. 2004. Critical Literacy as Comprehension: Expanding Reader Response. Journal of Adolescent Adult Literacy, 48(1): 52-62. https://doi.org/10.1598/JAAL.48.1.5

Mengis, J., Nicolini, D., \& Swan, J. 2018. Integrating Knowledge in the Face of Epistemic Uncertainty: Dialogically Drawing Distinctions. Management Learning, 49(5): 595-612. https://doi.org/10.1177/1350507618797216

Minkler, M. 1981. "Unfreezing” Lewin: The Case for Alternative Change Strategies in Health Education. International Quarterly of Community Health Education, 1(2): 169-182. https://doi.org/10.2190/FM63-4VN9-MKD7-X7DN

MoRST. 2007. Vision Màtauranga: Unlocking the Innovation Potential of Màori Knowledge, Resources and People. Wellington, New Zealand: New Zealand Government, Ministry of Research, Science+ Technology (MoRST).

Nicolini, D., Mengis, J., \& Swan, J. 2012. Understanding the Role of Objects in Cross-Disciplinary Collaboration. Organization Science, 23(3): 612-629.

https://doi.org/10.1287/orsc.1110.0664

Piggot-Irvine, E. 2009. Action Research in Practice. Wellington, New Zealand: New Zealand Council for Educational Research (NZCER) Press.

Rau, H., Goggins, G., \& Fahy, F. 2018. From Invisibility to Impact: Recognising the Scientific and Societal Relevance of Interdisciplinary Sustainability Research. Research Policy, 47(1): 266-276.

https://doi.org/10.1016/j.respol.2017.11.005

Reason, P., \& Bradbury, H. 2001. Handbook of Action Research: Participative Inquiry and Practice. London: SAGE.
Rewi, T., \& Rātima, M. 2018. Ngā Hurihanga o te Reo Māori i te Mātauranga: Changes in Māori Language Education. In M. Reilly, S. Duncan, G. Leoni, \& L. Paterson (Eds.), Te Koparapara: An Introduction to the Maori World: 304-323. Auckland, New Zealand: Auckland University Press.

Riel, M. 2010. Understanding Action Research. Research Methods in the Social Sciences, 17(1): 89-96.

Rowell, L. L., Bruce, C. D., Shosh, J. M., \& Riel, M. 2017a. The Palgrave International Handbook of Action Research. Basingstoke, UK: Palgrave Macmillan.

Rowell, L. L., Riel, M. M., \& Polush, E. Y. 2017b. Defining Action Research: On Dialogic Spaces for Constructing Shared Meanings. In The Palgrave International Handbook of Action Research: 85-101. Berlin: Springer.

Scheurich, J. J. 1995. A Postmodernist Critique of Research Interviewing. International Journal of Qualitative Studies in Education, 8(3): 239-252.

https://doi.org/10.1080/0951839950080303

Schuurbiers, D., \& Fisher, E. 2009. Lab-Scale Intervention. EMBO Reports, 10(5): 424-427. https://doi.org/10.1038/embor.2009.80

Seidel, V. P., \& O’Mahony, S. 2014. Managing the Repertoire: Stories, Metaphors, Prototypes, and Concept Coherence in Product Innovation. Organization Science, 25(3): 691-712. https://doi.org/10.1287/orsc.2013.0879

SfTI. 2018. Second Tranche Forward Strategy (2019-2024). New Zealand: Science for Technological Innovation (SfTI). https://www.sftichallenge.govt.nz/sites/default/files/2018-12/Future \%20Strategy\%20SfTI\%2020\%20June\%202018.FINAL_November.pdf

Smith, G. H. 2009. Mai i te maramatanga, ki te putanga mai o te tahuritanga: From Conscientization to Transformation. In Social Justice, Peace, and Environmental Education: 31-40. Abingdon, UK: Routledge.

Stappers, P. J. 2013. Prototypes as Central Vein for Knowledge Development. In L. Valentine (Ed.), Prototype: Design Craft in the 21st Century: 85-98. London: Bloomsbury Academic. https://doi.org/10.5040/9781350036031.ch-006

Stigliani, I., \& Ravasi, D. 2012. Organizing Thoughts and Connecting Brains: Material Practices and the Transition from Individual to Group-Level Prospective Sensemaking. Academy of Management Journal, 55(5): 1232-1259. https://doi.org/10.5465/amj.2010.0890

Tibbits, S. 2014. 4D Printing: Multi-Material Shape Change. Architectural Design, 84(1): 116-121.

https://doi.org/10.1002/ad.1710

Tibbits, S., McKnelly, C., Olguin, C., Dikovsky, D., \& Hirsch, S. 2014. 4D Printing and Universal Transformation. In Proceedings of the 34th Annual Conference of the Association for Computer Aided Design in Architecture: 539-548. Los Angeles, October 23-25, 2014.

Weller, C., Kleer, R., \& Piller, F. T. 2015. Economic Implications of 3D Printing: Market Structure Models in Light of Additive Manufacturing Revisited. International Journal of Production Economics, 164: 43-56. https://doi.org/10.1016/j.ijpe.2015.02.020

Zeidler, H., Klemm, D., Böttger-Hiller, F., Fritsch, S., Le Guen, M. J., \& Singamneni, S. 2018. 3D Printing of Biodegradable Parts Using Renewable Biobased Materials. Procedia Manufacturing, 21: 117-124. https://doi.org/10.1016/j.promfg.2018.02.101 


\section{TIm Technology Innovation Management Review}

\section{Academic Affiliations and Funding Acknowledgements}
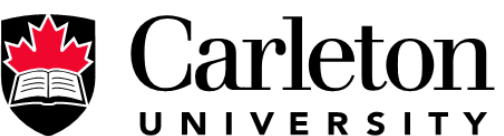

U N I V E R S I T Y

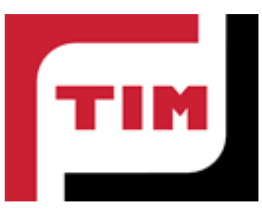

Technology Innovation Management (TIM; timprogram.ca) is an international master's level program at Carleton University in Ottawa, Canada. It leads to a Master of Applied Science (M.A.Sc.) degree, a Master of Engineering (M.Eng.) degree, or a Master of Entrepreneurship (M.Ent.) degree. The objective of this program is to train aspiring entrepreneurs on creating wealth at the early stages of company or opportunity lifecycles.

- The TIM Review is published in association with and receives partial funding from the TIM program. 